\title{
ARBEIDERS-KOLONIES ALS MIDDEL TOT WERING VAN BEDELARIJ.
}

Voor eenigen tijd verscheen van de hand van den heer E. Robin, predikant te Parijs en Secretaris der Vereeniging: „Maison hospitalière pour les ouvriers sans asile et sans travail" een werk getiteld: "Hospitalité et travail ou des moyens préventifs de combattre la mendicité et le vagabondage", dat ten volle verdient ook bij ons te lande in wijder kring bekend te worden.

Het onderwerp dat de schrijver met groote kennis van zaken behandelt, is ook voor ons van overwegend belang. Het is nl. zijn streven om eene oplossing te vinden van het vraagstuk dat tegenwoordig in alle landen zoovele gemoederen bezig houdt: op welke wijze men de werkeloozen kan te hulp komen en tevens de bedelarij onderdrukken.

De schrijver, die door zijn werkkring ten volle bekend is met de treurige toestanden die in geheel Frankrijk en met name in Parijs in dit opzicht bestaan, acht het oogenblik dáár om tusschenbeide te komen.

Parijs werkt ten opzichte van het overige Frankrijk eenigzins als een magneet. In die groote stad gewijd aan den arbeid en aan het genoegen schijnt voor een ieder plaats te zijn, en tal van arbeiders bevinden zich dan ook in dien voortdurenden stroom van menschen, die eer en fortuin in de hoofdstad trachten te verwerven.

Toen de industrie bloeide en er in alle vakken handen te kort kwamen, werden de verwachtingen in den regel niet beschaamd, maar toen er een achteruitgang in de productie plaats vond, gebeurde het maar al te vaak dat de jonge werkman, dio met zooveel illusies de wereldstad was binnengetreden, geen werk kon vinden. De spaarpenningen waren spoedig opgeteerd en er bleef den ongelukkige niets anders over dan te gaan bedelen. Door de policie als landlooper gevat on veroordeeld, maakte hij kennis met de bedelaars en landloopers van beroep, en maar al te vaak

LiCoN. 1887. 
bleek het dat op deze wijze de carrière van den werkman voor altijd was gebroken.

Het zijn vooral deze en soortgelijke feiten die den heer Robin er toe brachten om te spreken. Met kracht van overtuiging wees hij op het onbillijke van dien toestand, want het gaat toch niet aan om den man, die geen werk kan vinden en bijgevolg niet in eigen onderhoud kan voorzien, op gelijke lijn te stellen met den bedelaar en den landlooper, die uit luiheid hun schandelijk beroep uitoefenen.

Schrijver gaat in bijzonderheden na hoo deze zaak in het buitenland is geregeld. Engeland stelt zijn werkhuizen open voor een ieder die zich aanmeldt; tegen een zekere verplichte hoeveelheid arbeid worden nachtverblijf en kost verstrekt. Dit systeem van werkhuizen heeft voorzeker zijn goede zijde, maar toeh is het er verre van daan dat deze wijze van doen de beste oplossing aan de hand geeft. Althans van Engelsche zijden is herhaaldelijk met nadruk gewezen op de nadeelen die aan dit systeem verbonden zjn. $\left(^{*}\right)$

Het stelsel van armenzorg in Holland wordt met voorliefde door den schrijver besproken. Daar toch werd onder gelijke wetgeving als in Frankrijk, een andere weg ingeslagen die tot betere uitkomsten leidde. De strafkolonien Veenhuizen en Ommerschans en de vrije kolonien te Frederiksoord worden uitvoerig beschreven en het is duidelijk te zien hoezeer de schrijver ingenomen is met hetgeen in Nederland op het gebied van armenzorg is tot stand gebracht. Hij wenscht dan ook dat in Frankrijk dergelijke bedelaars-kolonion en vrije kolonien mogen verrijzen, die voor een goed deel beantwoorden aan de wenschen die hij zich stelt.

De schrijver ziet hier echter wel eenigszins over het hoofd dat aan de strafkolonien ook het groote nadeel kleeft, dat aldaar geen voldoend onderscheid wordt gemaakt tusschen de bedelaars van beroep en hen die door den nood tot bedelen zijn gebracht. Schrijver heeft ook een eenigzins verkeerd begrip van de uitkomsten met de bedelaars-kolonien verkregen. Hij gaat uit van het denkbeeld dat iemand die in Veenhuizen zijn straftijd heeft ondergaan, werken heeft geleerd. Dit nu is bezijden de waarheid. Veenhuizen is allerminst een verbeteringsgesticht; het is wel eens, en tot zekere hoogte terecht, de hoogeschool voor de misdadigers genoemd. Voorzeker is er reden om dankbaar te zijn

(*) Nog onlangs door Herbert V. Mills in zija "Poverty and the State." 
dat in Nederland het stelsel der strafkolonien bestaat, want er zijn weinig landen waar zoo weinig bedelaars worden gevonden als bij ons; dat is een feit hetwelk ieder vreemdeling treft, die ons land bezoekt. Maar toch ware het wenschelijk dat naast die bedelaars-kolonien voor de luiaards, nog andere inrichtingen verrezen voor de bedelaars uit nood.

Het stelsel van armenzorg in Zwitserland wordt uitvoerig besproken en het is opmerkelijk hoezeer in dat kleine land op gelukkige en verlichte wijze deze materie is geregeld. Men is daar doordrongen van de waarheid dat door het geven van aalmoezen de bedelaars gemaakt worden, en men heeft in de meeste steden, met name in Lausanne en in Genève, een stelsel toegepast dat in vele opzichten overeenkomt met het stelsel dat zoo zegenrijk werkt in Elberfeld en dat algemeen bekend is als het Elberfeldsche stelsel. In hoofdzaak berust dit hierop: 10. dat nimmer aalmoezen worden gegeven dan na voldoend onderzoek en dat alle gegoede burgers verplicht zijn om het toezicht te houden over eenige bepaald aangewezen arme gezinnen, waarvan zij dus al het ware als voogden optreden.

Dit stelsel, dat gegrond is op een verlicht besef van burgerplicht, heeft bewonderenswaardige vitkomsten opgeleverd, en voor niet te groote steden biedt deze wijze van armenzorg voorzeker groote voordeelen.

Het was echter vooral in Duitschland dat schrijver kennis maakte met een stelsel dat zijne volkomen goedkeuring wegdraagt en dat dit ook zoker ten volle verdient. Daar dit stelsel ook bij ons te lande te weinig bekend is en zeer geschikt om te worden nagevolgd, stel ik mij voor in de volgende bladzijden er een kort overzicht van te geven.

De arbeiders-kolonies in Duitschland danken hun ontstaan aan den predikant von Bodelschwing. De groote menigte arbeiders, die in Duitschland zonder yast werk en zonder vaste woonplaats waren, brachten hem op het denkbeeld dat het eene daad van algemeen belang, zoowel als van menschelijkheid zou zijn, om die lieden de gelegenheid te verschaffen om werk te verrichten, voornamelijk bij ontginning van woesten grond, en om hen op die wijze terug te houden van de misdaad. Zijn denkbeelden vonden algemeen ingang en zoo werd in 1882 de eerste kolonie, Wilhelmsdorf bij Bielefeld, gesticht. Sedert zijn nog 15 zulke kolonies verrezen en de $16 \mathrm{e}$ is in wording. In de maand Augustus van het vorig jaar hadden sedert hare cprichting reeds meer dan 15,000 
personen hulp genoten en in diezelfde jaren was het aantal veroordeelingen wegens landlooperij met 2250 verminderd, vergeleken met de vorige jaren. Zulke cijfers zijn welsprekend en er valt dan ook bijna niet te twijfelen aan de levenskracht van deze jeugdige arbeiders-kolonies.

De gelden voor de inrichting van de eerste kolonie werden verstrekt deels door vrijwillige bijdragen en contributies van leden, deels door subsidies van wege de provincie. Het geheele terrein der eerste kolonie is 166 hectaren groot en kostte bij aankoop $f 36000$. Naar gelang dat er ruimte is wordt een ieder die zich aanmeldt in de arbeiders-kolonie opgenomen. Er wordt niet gevraagd naar godsdienstige belijdenis of naar het verleden. De kolonist verbindt zich echter formeel dat hij erkent dat het een weldaad is dat hij wordt opgenomen en dat hij geen aanspraken hoegenaamd kan doen gelden; hij verklaart dat hij bewust is dat hij voor zijn arbeid voldoende beloond wordt door de genoten ligging en voeding en dat alles wat hem bovendien wordt verstrekt een weldaad is waarop hij geenerlei recht heeft. Bovendien moet hij verklaren dat hij zich bewust is dat hij onmiddellijk zal worden verwijderd als zijn gedrag daar aanleiding toe geeft en hij daardoor al hetgeen hem mocht zijn toegezegd, onherroepelijk verbeurt. Het werk dat verricht wordt bestaat des winters hoofdzakelijk in graafwerk als middel tot ontginning en in den zomer in landbouwwerk. Bovendien wordt huisarbeid verricht zooals kleedermaken, schoenmaken enz., doch uitsluitend voor het eigen gebruik in de kolonie. De kolonisten dragen geen uniforme kleeding, doch zoo noodig worden zij wel van kleederen voorzien. Deze moeten zij echter zelf door hun arbeid verdienen; zij kunnen nl. van 10-25 cents daags verdienen, welk bedrag in het credit op hun boekje wordt gebracht, hetgeen in de eerste plaats dient om de kosten van kleeding, gereedschappen enz. te vergoeden.

Gewoonlijk blijven de kolonisten drie of vier maanden. $Z_{\mathrm{ij}}$ hebben dan hun kleeding afbetaald en ten gevolge van de goede, gezonde voeding zijn zij weer voldoende bij krachten om zelfstandig op te treden. Het bestuur der kolonie biedt hun zooveel mogelijk de behulpzame hand, door hen in verbinding te brengen met arbeidgevers.

Nauwelijks was de eerste kolonie geopend of tal van lieden boden zich aan om te worden opgenomen. Dit getal was zoo groot dat er geen denken aan was ze allen toe te laten, zoodat door 
het aanvankclijk succès aangespoord tegenwoordig reeds 15 van zulke arbeiders kolonies bestaan. Onderstaand staatje, tot 31 Augustus bijgewerkt, geeft een overzicht van eenige bijzonderheden die hierop betrekking hebben.

\begin{tabular}{|c|c|c|c|c|}
\hline NAAM DER KOLONIE. & $\begin{array}{l}\text { DATUM VAN } \\
\text { STICHTING. }\end{array}$ & 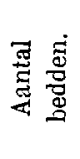 & $\begin{array}{c}\text { Aantal } \\
\text { kolonisten } \\
\text { sedert de } \\
\text { oprichting } \\
\text { verpleegd. }\end{array}$ & $\begin{array}{c}\text { Aantal } \\
\text { op } 31 \\
\text { Augustus. }\end{array}$ \\
\hline Wilhelmsdorf (Westphalen). & 22 Maart 1882 & 360 & 3645 & 90 \\
\hline Kästorf (Hannover) & 24 Juni 1883 & 150 & 1395 & 126 \\
\hline Rickling (Schleeswijk-Holstein) & 10 oct. 1883 & 150 & 1865 & 111 \\
\hline Friedrichsville (Brandenburg). & 13 Nov. 1883 & 175 & 1706 & 112 \\
\hline Dornahof (Wurtemberg) & 15 Nov. 1883 & 100 & 870 & 50 \\
\hline Seyda (Prov. Saksen) & 14 Dec. 1883 & 150 & 1369 & 79 \\
\hline Dauelsberg (Oldenburg). & 8 Febr. 1884 & 50 & 570 & 42 \\
\hline Wunscha (Silezië) . . . . . . & 14 Juli 1884 & 100 & 551 & 85 \\
\hline Meierei (Ponmeren). . . . . & 25 Juli 1884 & 150 & 794 & 67 \\
\hline Carlshof (Oost Pruissen) & 15 Oct. 1884 & 150 & 875 & 30 \\
\hline Berlin. & 1 Dec. 1884 & 62 & 508 & 29 \\
\hline Ankenbuch (Baden) & 26 Febr. 1885 & 50 & 256 & 34 \\
\hline Nieuw Ulrichstein (Hessen). & $1 \mathrm{Juli} \quad 1885$ & 100 & 332 & 35 \\
\hline Lühlerheim (Rijnstreek) & 15 Febr. 1886 & 120 & 336 & 119 \\
\hline Scheckengrün (Kon. Saksen). & 22 Febr. 1886 & 120 & 264 & 94 \\
\hline
\end{tabular}

Het bestuur van deze kolonies is gelijk. Aan het hoofd staat eene commissie, waarvan een klein aantal leden als dagelijksch bestuur optreden. Een predikant of een R. C. priester is, al naar gelang van de behoefte, aan dit bestuur toegevoegd. Het Comité benoemt een bestuurder, die in staat is om de leiding op zich te nemen, zoowel van het eigenlijke gesticht als van de landelijke werkzaamheden daarbuiten. Tot voor korten tijd hadden deze bestuurders uitsluitend hun opleiding ontvangen in het Rauhe-haus bij Hamburg. Dit is een soort vakschool voor hen die zich willen bekwamen om later aan het hoofd te staan van philantropische instellingen en alwaar tal van uitstekende mannen gevormd zijn. Daar dit aantal echter niet voldoende is, werd besloten om deze bestuurders ook van elders te nemen, zoo zij slechts voldoende waarborgen aanboden dat zij hunne moeielijke taak naar behooren zouden volbrengen.

De verschillende kolonies staan niet afgezonderd van elkaar. Een centraal comité gevestigd te Meistrau in de prov. Brandenburg en bestaande uit 2 gedelegeerden van de verschillende comités 
vormt het hoofdbestuur on stelt de hoofdreglementen voor de verschillende kolonies vast. Bovendien wordt een orgaan uitgegeven, getiteld: "Die Arbeiterkolonie," waarin alle zalken die hierop betrekking hebben worden behandeld, en hetwelk maandelijks verschijnt.

Hoe nitgebreid deze organisatie ook moge zijn, toch bleek zịj nog niet in staat om in alle aanvragen van werk te kunnen voorzien. Van daar dat besloten werd tot de oprichting van kleinere kolonies (Arbeiter $Z$ weigkolonien). Deze liggen verspreid in de Provincies en worden bij voorkeur gevestigd op plaatsen waar tijdelijk veel arbeidskrachten worden gevorderd, bijv. bij aanleg van kanalen, van spoorwegen en van dergelijke werkzaamheden.

Deze kolonies zijn op zeer eenvoudigen voet ingericht; aan het hoofd staat een bestuurder, die soms ook als opzichter werkzaam is bij het werk dat wordt ondernomen. In den regel zijn 20-30 kolonisten in zulk eene kolonie vereenigd; zij wonen in een barak en verrichten hun werk hoofdzakelijk ter vergoeding van de ontvangen voeding, kleeding en nachtverblijf. In den regel belast zich een comité, bestaande uit den burgemeester, den predikant, den kantonrechter of andere geschikte personen met het toezicht op deze kolonies, die in alle opzichten op dezelfde leest geschoeid zijn als de Arbeiter-kolonien, met dien verstande dat alles op veel kleiner voet is ingericht en dat zij zonder groote kosten kunnen worden verplaatst als de werkzaambeden in een bepaalde streek ophouden.

Eon ander onderdeel van deze groote organisatie bestaat in het vestigen van herbergen voor rondtrekkende werklieden, die zonder middel van bestaan zijn. Voornamelijk zijn zij bestemd voor de opname van zulke werklieden, die zich naar eene der arbeiders-kolonies wenschen te begeven. Zij zijn dan ook op ongeveer een dagreize van elkander verwijderd, zoodat zij een aaneengesloten keten vormen. Al deze herbergen zijn zooveel mogelijk op gelijken roet ingericht.

De kosten worden gedragen door de gemeentebesturen en andere corporaties. Zij zijn gelegen op afstanden, die niet zoo groot zijn dat de reizigers genoodzaakt zouden zijn om te bedelen voor nachtverblijf.

De ligging en de voeding worden kosteloos verstrekt, maar tegen eene zekere hoeveelheid te verrichten arbeid.

Niemand, die in het bezit is van eigen middelen, mag zich tot onderkomen aanbieden; een ieder is gewaarschuwd dat hij wegens 
oplichterij zal worden vervolgd zoo hij hulp vraagt, welke later blijkt niet noodig te zijn geweest.

Geschiedt de aanvrage om nachtverblijf door iemand die in kennelijken staat van dronkenschap verkeert; is hij brutaal of weigert hij om te werken, zoo wordt hij niet alleen weggezonden maar ook gesignaleerd aan de politie.

In elk van deze herbergen is een informatiebureau gevestigd waar de arbeidgevers zich kumnen vervoegen zoo zij arbeiders in hun dienst wenschen te nemen.

Door verschillende vereenigingen tot wering van bedelarij wordt het benoodigde werk verschaft waarmede de gasten bezig gehouden kunnen worden. Ook de gemeentebesturen trachten zooveel mogelijk hierin te hulp te komen door geschikt werk ter beschikking te stellen.

Behalve deze herbergen, die grootendeels van overheidswege worden bekostigd, zijn er nog andere, die worden onderhouden door de particuliere weldadigheid. Het zijn de zoogenaamde Herbergen zur Heimath. Het godsdienstig karakter treedt hier, evenals in de arbeiderskolonies meer bepaald op den voorgrond, terwijl aan het hoofd dezer herbergen zooveel mogelijk mannen worden geplaatst op wier karakter men vast kan vertrouwen on die meestal hun opleiding hebben genoten in het Rauhe-Haus. Ook aan deze inrichtingen is een informatiebureau verbonden, zoodat zij evenals de arbeiders-kolonies en de arbeiders-horbergen eenigszins in de plaats treden van arbeidsbeurzen.

Uit bovenstaande schets kan men zich een denkbeeld vormen van den omvang dien deze organisatie in Duitschland heeft verkregen en zoowel uit een moreel als uit een sociaal oogpunt zijn de verkregen uitkomsten in de hoogste mate bevredigend.

Men wenscht nu echter daar te lande nog een stap verder te gaan door het oprichten van kolonies, overeenkomende met de kolonies der Maatschappij van Weldadigheid, alwaar de beste elementen uit de arbeiderskolonien zich zouden kunnen vestigen en waar zij in de gelegenheid zouden worden gesteld om een woning en een stukje grond in eigendom te verkrijgen.

Dit denkbeeld wordt ook weder door den heer Robin uitgewerkt, die in de vrije Kolonien van Weldadigheid, zooals zij te Frederiksoord worden gevonden, de verwezenlijking ziet van een zijner idealen. Het is merkwaardig hoezeer deze kolonies in de laatste jaren de aandacht hebben getrokken in het buitenland, en hoe in buitenlandsche geschriften dit onderwerp wordt behandeld. Behalvo het bovengenoemde werk van den Parijschen predikant, 
komt eene uitvoerige beschrijving voor in het werk van den heer Herbert V. Mills, getiteld: Poverty and tho State, terwijl van de hand van den beer Tallack, Secretary of the Howard Association in Londen, zoowel in de Times als in andere tijdschriften hoogst welwillende beschouwingen over de Maatschappij van Weldadigheid werden geleverd. Ook in Duitschland en wel voornamelijk van de zijde van het bestuur der arbeiderskolonien is de aandacht in den laatsten tijd er ten zeerste op gevestigd, en in het officieele tijdschrift "die Arbeiter Kolonie" kwam onlangs een zeer waardeerend schrijven voor over de stichting van Generaal van den Bosch. Eindelijk werd nog zeer onlangs door den Heer Louis Le Grand, Gezant van Frankrijk in Nederland, eene beschouwing geleverd over de Maatschappij van Weldadigheid in eene vergadering van de Académie, die van groote waardeering getuigt.

Het valt niet te ontkennen dat de stichting van zulke kolonies, alwaar, op het voetspoor der Maatschappij van Weldadigheid, aan geheele huisgezinnen een zelfstandig bestaan wordt verzekerd, iets zeer aantrekkelijks heeft.

De geschiedenis van de Maatschappij van Weldadigheid is echter dáár, om te bewijzen met hoeveel bezwaren men bij de uitvoering van dit plan zal te kampen hebben. Het is toch heel iets anders of men in gestichten alleenloopende personen tijdelijk bijeenbrengt en hen aan den arbeid zet, of dat men zich belast met de zorg van geheele gezinnen aan wie men ò een voortdurende pacht of wel eigendomsrecht van den grond in uitzicht stelt. Zulk eene bevolking breidt zich door geboorte bij voortduring uit; men moet zich belasten met velerlei zorgen, men neemt als het ware de zedelijke verplichting op zich om voor de opleiding van de kinderen te zorgen door het verstrokken van onderwijs, terwijl de kosten van administratie, van onderhoud en van toezicht ongelijk veel hooger zijn dan wanneer men te doen heeft met eene vlottende bevolking, die in gestichten bijeen is. Hier meer dan elders zal het noodig zijn om alvorens uitvoering aan die plannen te geven, de vermoedelijke kosten wel te berekenen. En dan zou het mij wenschelijker voorkomen, voornamelijk uit een geldelijk oogpunt, om die gezinnen niet in groote kolonies te vereenigen, maar hen te verspreiden in kleine groepen in verschillende landelijke gemeenten. Men zou hun daar kunnen helpen aan woning en grond, en men zou ze dan tot een zekere hoogte aan hun lot kunnen overlaten, behoudens eenige bepalingen waaraan zij zich zouden moeten blijven onderwerpen. Dronken- 
schap, politieo-vertredingen en dergelijken zouden ten gevolge moeten hebben dat de goedgunstige bepalingen ten humnen opzichte werden ingetrokken, terwijl men door een geregeld plaatselijk toezicht zich kon overtuigen dat b.v. de opvoeding der kinderen niet werd verwaarloosd. Op die wijze zou men zich niet behoeven te belasten met een uitgebreide organisatie, men zou geen scholen en kerken behoeven te bouwen; hoogstens zou men kunnen trachten door werkverschaffing op kleine schaal de gezinnen in de wintermaanden aan het werk te houden.

Wanneer men op het geld niet behoefde te zien, dan zou het stichten van vrije arbeiders kolonien, op gelijke leest geschoeid als die door van den Bosch gesticht voorzeker de voorkeur verdienen. Doch hoezeer men zich ook de ervaring hier te lande opgedaan, kan ten nutte maken, toch zou ik vreezen dat uit een geldelijk oogpunt groote teleurstellingen te wachten zouden zijn. De Maatschappij van Weldadigheid heeft haar Sturm und Drangperiode achter den rug en langzamerhand is voor haar een tijdperk aangebroken van betrekkelijken voorspoed. Zij kan zich nu gerust ontwikkelen en het staat te bezien dat zij op velerlei gebied zoo van armenzorg en van weezenverpleging, als van ontginniug en van vakonderricht $\left(^{*}\right)$ nog gewichtige diensten aan den lande zal kunnen bewijzen. Maar toch mag men in gemoede vragen: wanneer de stichters van te voren hadden kunnen voorzien welke schatten hiermede gemoeid zouden zijn, of zij dan tot de oprichting zouden hebben besloten.

Hoo het zij, Nederland mag er trotsch op zijn dat hare vrije arbeiders kolonies bij roortduring het hoofd hebben kunnen bieden aan de groote moeielijkheden die haar bestaan bedreigden, want voorzeker behoort deze stichting voor armenzorg tot de meest merkwaardige instellingen, die op dit gebied zijn. tot stand gekomen.

Maar zou het omgekeerd ook niet wenschelijk zijn dat bij ons te lande het voorbeeld door Duitschland gegeven werd nagevolgd, en dat naast de stichting van Generaal van den Bosch de stichting van Dr. Bodelschwing verrees?

Reeds zijn er bij ons te lande van verschillende zijden stemmen opgegaan, die de wenschelijkheid hiervan hebben bepleit en de uitstekende uitkomsten in Duitschland verkregen, zouden ook hier

(*) Men deuke aan de mandenmakerijen, waardoor cen nieuwe tak van iudustrie in ons land werd gevestigd; aan de Gerard Adriaan vau Swieten 'Tninbouwschool en aan de weldra op te richteu School voor boschbazen. 
het succès waarborgen. Het zou een uitkomst zijn voor die ongelukkigen, die ook bij ons te lande tegenwoordig zooveel gevonden worden, die werk zoeken maar het niet kunnen vinden. Deze vervallen nu aan de openbare weldadigheid of, zoo zij gaan bedelen, staan de Rijks bedelaarsgestichten voor hen open. Met al de nadeelen die aan die bedelaarskolonies verbonden zijn, mag men Nederland toch gelukkig heeten dat zij bestaan. Voor de bedelaars van professie zijn zij toch een allergeschiktst ballingsoord, maar van den anderen kant zijn zij voor de ongelukkigen, die. door het ongeluk tot den bedelstaf zijn gebracht de meest ongeschikte plaats van verblijf, die men zich denken kan.

De invloed van al die liederlijke sujetten werkt verpestend op de betere elementen, die daaronder mochten worden gevonden en wel verre dat een verblijf in deze gestichten een heilzamen iuvloed uitoefent, zooals de heer Robin meent, zullen allen die met deze kolonies nader bekend zijn u weten te verhalen dat de gevallen dat iemand, die in Veenhuizen geweest is nog weder terecht komt tot de hooge uitzonderingen behoort.

Hoe geheel anders is het getuigenis dat wordt gegeven van de Duitsche arbeiderskolonies. Voorzeker, er is een groot onderscheid tusschen de soort van personen die wordt opgenomen. Hier zijn het landloopers on bedelaars van beroep, die als het ware worden geïnterneerd om hen onschadelijk te maken, dáár zijn het verdoolden en ongelukkigen, die liefderijk worden opgenomen en door het aankweeken van godsdienstigen zin, door orde en werkzaambeid worden opgebeurd en geschikt gemaakt om een nieuw leven te beginnen.

Voorwaar, het ware te wenschen dat zulke arbeiderskolonies ook bij ons te lande mochten verrijzen. Het tijdstip is zeker gunstig om deze plannen op touw te zetten, want meer en meer begint men ook bij ons te lande het groote belang der arbeiderskwestie in te zien.

En het geldt hier niet het doen van een sprong in het duister, het is niet het jagen om een onuitvoerbaar plan ten uitvoer te leggen. Neen, de ondervinding in Duitschland opgedaan staat ons er borg voor dat zulke arbeiderskolonies ook bij ons te lande een dankbaar, een hoogst nuttig arbeidsveld zouden vinden waarvan de zegenrijke gevolgen aan Staat en maatschappij zouden ten goede komen.

Frederiksoord.

F. B. Löнnis. 